\title{
HAEMOLYTIC ANAEMIA OF MECHANICAL ORIGIN AFTER OPEN HEART SURGERY
}

\author{
BY \\ H. M. SAYED,* J. V. DACIE, D. A. HANDLEY, S. M. LEWIS, AND W. P. CLELAND \\ From the Departments of Surgery and Haematology, Postgraduate Medical School of London
}

(RECEIVED FOR PUBliCATION AUGUST 23, 1961)

Severe haemolytic anaemia as a complication of open cardiac surgery has not, we believe, previously been reported. The purpose of this paper is to draw attention to its occurrence by describing a case and to indicate its probable cause and prevention.

\section{CASE RePort}

A. A., a man aged 25 years, was found to have a cardiac murmur at the age of 8 years, but he had led a normal active life and has experienced no symptoms of cardiac origin. However, when examined in September, 1960, his heart was found to be moderately enlarged and there was evidence of left ventricular hypertrophy. An electrocardiogram showed a prolonged P-R interval, right bundle-branch block, and left axis deviation.

Cardiac catheterization studies revealed a left-toright shunt, mainly at ventricular level; the pulmonary:systemic flow ratio was estimated to be $2.8: 1$, with normal pulmonary arteriolar resistance. A ventricular septal defect, probably accompanied by an atrial septal defect, was diagnosed and it was decided that an operation for the repair of the defect was desirable.

The patient's general health was good ; in particular his blood picture was normal (haemoglobin, $15.1 \mathrm{~g}$. per $100 \mathrm{ml}$,, leucocytes, 5,000 per c.mm., and erythrocytes normal in appearance).

First Operation (October 12, 1960).--The heart was exposed with the aid of extracorporeal circulation and body cooling to $29^{\circ} \mathrm{C}$. An ostium primum defect, $4 \times 3 \mathrm{~cm}$. in size, was found and there was evidence also of slight mitral incompetence through what appeared to be a small cleft at the free border of the aortic septal cusp. The defect in the septum was repaired using a patch of Teflon feit 1/16 in. in thickness. This was sutured to the margins of the defect. No attempt was made to repair the defect in the mitral cusp (Fig. 1).

The immediate post-operative course was initially good, but by the eighteenth day after the operation the patient's temperature had risen to $100^{\circ} \mathrm{F}$. and

\footnotetext{
* Lecturer in thoracic surgery, Ein Shams University, Cairo.
}

he was noticed to be pale and jaundiced. His urine was found to be dark brown-red, and the patient said that he believed he had passed dark brown urine ever since the operation.

LABORATORY INVESTIGATIONS.-The haemoglobin was 6.5 g. per $100 \mathrm{ml}$. (43\%) with $7.7 \%$ of reticulocytes. The total leucocyte count was 3,000 per c.mm. ; the platelet count 214,000 per c.mm. Stained films showed the presence of many cells which were irregular in shape ; some showed irregular crenation, others were cell fragments of irregular shape; still others had small projections ("burrs") from their surface (Fig. 2). In addition polychromasia was conspicuous, but typical spherocytes were not seen. No Heinz bodies were present.

The patient's serum was yellowish brown and contained free haemoglobin and methaemalbumin. Haptoglobins were absent. The serum bilirubin level was $1.6 \mathrm{mg} . / 100 \mathrm{ml}$., serum proteins $7.7 \mathrm{~g} . / 100 \mathrm{ml}$. with an albumin: globulin ratio of 1.7 .

The direct antiglobulin (Coombs) test was negative and no abnormal antibodies could be demonstrated in the patient's serum using normal or trypsinized erythrocytes. Serum complement was normal and Ham's acidified-serum test was negative. The patient's blood group was $\mathbf{A B}, \mathbf{R h}$-positive.

The osmotic and mechanical fragility of the erythrocytes was normal. The glutathione stability and glucose 6-phosphate dehydrogenase activity of the erythrocytes were also normal. No abnormal haemoglobins were present. Coagulation studies revealed no abnormalities. Blood cultures were sterile except on one occasion when Staphylococcus albus was isolated; this was considered to be a contaminant.

It was clear from the above studies that the patient was suffering from an unusual type of haemolytic anaemia characterized by intravascular haemolysis. This, in fact, persisted virtually unchanged in severity until it ended after a second operation carried out six months later (see below).

It was found necessary to transfuse the patient repeatedly during the period of haemolytic anaemia, and he received in all 60 bottles of blood (approximately 25 litres) during the six-months period (Fig. 3). Haemolysis was uninfluenced by prednisone $(\mathbf{4 0} \mathrm{mg}$. daily for three weeks) and by taking the patient off 

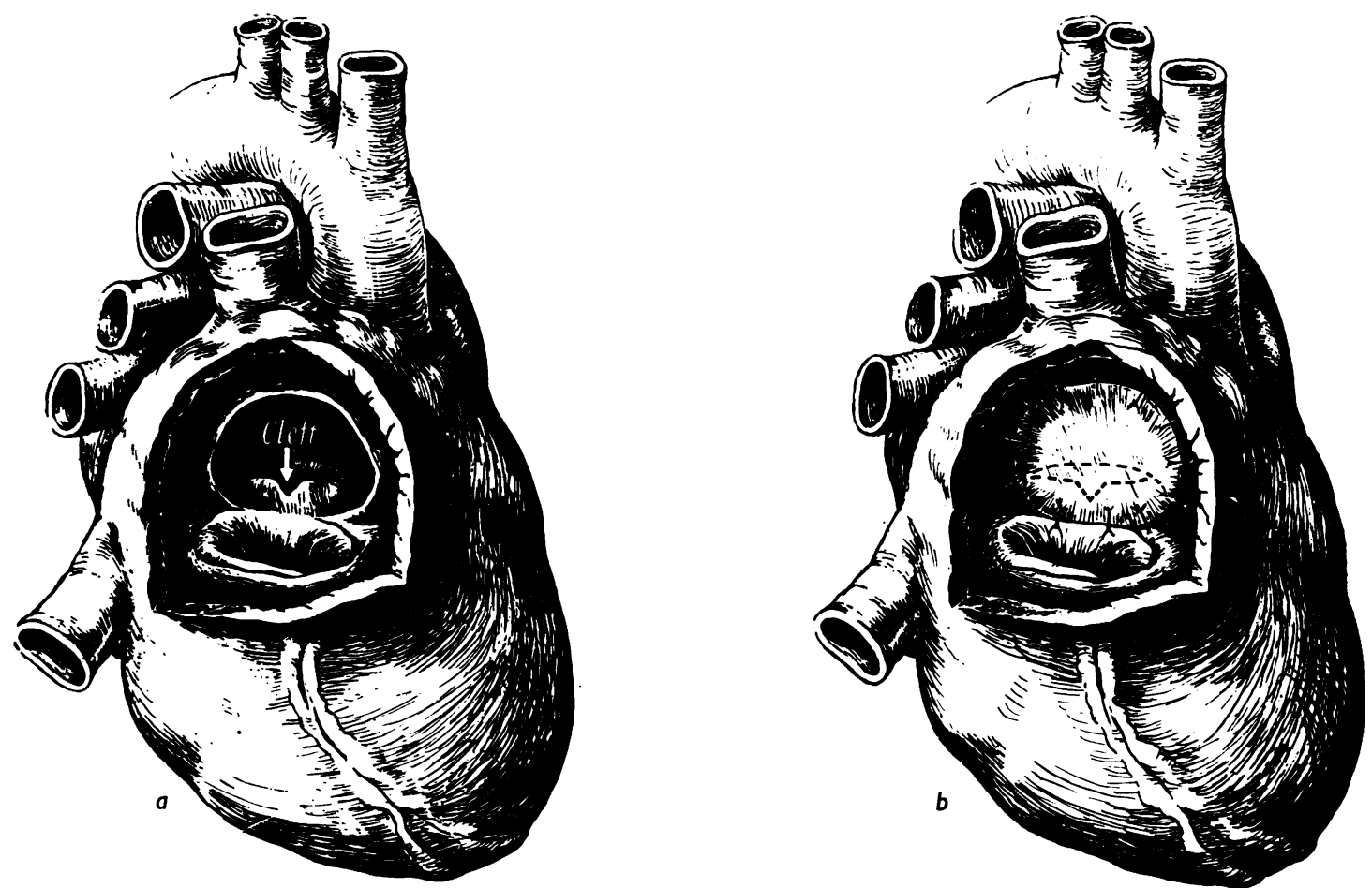

Fig. 1.-(a) Illustration showing the atrial_septal defect, as viewed from the right atrium, and the partial cleft in the mitral valve. (b) Illustration of the repair of the defect by a Teflon patch.

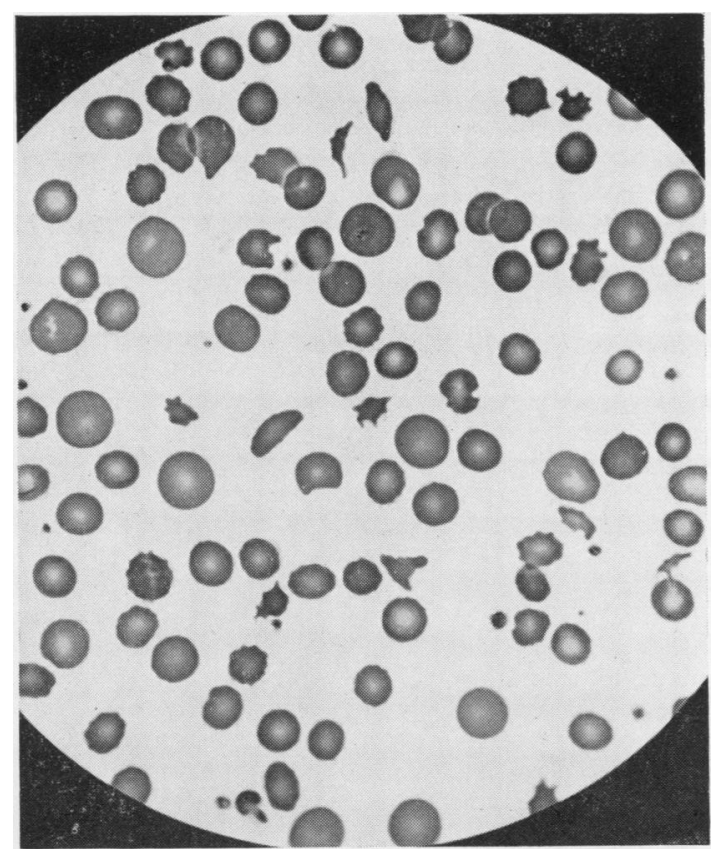

Fig. 2.-Photomicrograph of a blood film of the patient a short time after the first operation. Many irregularly crenated cells and cell fragments are present. $\times 700$. various drugs which he had been receiving (sulphadimidine, digoxin, sodium amytal, and ferrous gluconate).

FURTHER STUDiEs.-Normal compatible erythrocytes were labelled with ${ }^{51} \mathrm{Cr}$ on three occasions and their life span estimated. They were eliminated unusually rapidly, and their mean life span was estimated to be between six and nine days on the three different occasions.

A number of 24-hour collections of urine were made and the total haem pigments estimated by the benzidine method. Between $2.6 \mathrm{~g}$. and $6.0 \mathrm{~g}$. haemoglobin was excreted per day (mean, $4.5 \mathrm{~g}$.).

Plasma haemoglobin was estimated, too, on a number of occasions and values varying between 150 and $316 \mathrm{mg}$. per $100 \mathrm{ml}$. were found (mean, $208 \mathrm{mg}$., 17 observations).

As it was thought that haemolysis was probably occurring locally in the heart, further catheterization studies were undertaken to try to see if evidence in support of this could be obtained.

There was no evidence of a shunt, confirming that the defect was closed. Furthermore, as there was a low pulmonary capillary wedge pressure (mean, $8 \mathrm{~mm}$. $\mathrm{Hg}$ ) it was concluded that there was no significant mitral incompetence. Samples of mixed venous blood, pulmonary arterial blood, and brachial arterial blood were tested for their plasma haemoglobin content. The results were 302,292 , and $303 \mathrm{mg}$. per $100 \mathrm{ml}$., 


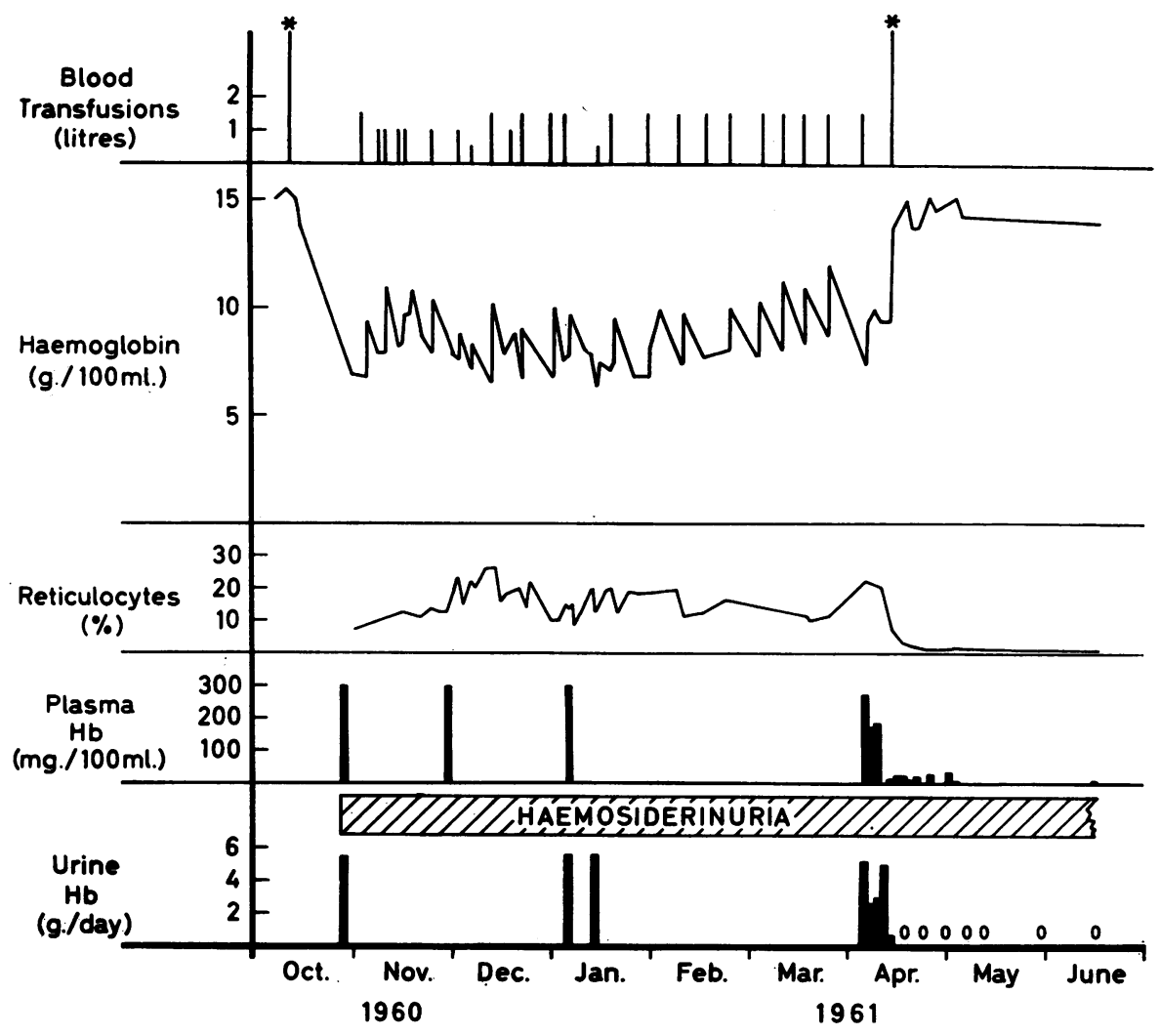

Fig. 3.-Observations on the haematological changes and the patient's transfusion requirements. During each of the operations* 20 bottles of blood (10 litres) were used in association with an extracorporeal circulation.

respectively, differences which were not thought to be significant.

All the studies referred to above indicated that the patient was suffering from intravascular haemolysis. The fact that the patient's blood was normal before operation suggested strongly that the haemolysis was in some way a consequence of the operation on the heart. The appearance of the blood film, in particular the presence of fragments of erythrocytes and the fact that haemolysis was intravascular, suggested that haemolysis might in some way be traumatic (mechanical) in origin.

The fact that normal erythrocytes were haemolysed rapidly meant that an intrinsic abnormality of the patient's own cells could not be the basis of the haemolysis. This was supported, too, by the normal results of the various tests carried out on the patient's cells. The repeatedly negative antiglobulin test and the failure to demonstrate any abnormal antibodies in the patient's serum, and the normal serum complement level in the presence of intravascular haemolysis, made an immune mechanism of haemolysis most unlikely.

As a working hypothesis it was considered that the Tefion felt patch had not become covered with a complete endothelial lining due to the impact of a regurgitant jet of blood on the patch, and that the haemolysis was occurring as the result of this impact between erythrocytes and bare Teflon felt.

In vitro, it could be shown that Tefion felt was not entirely harmless. Volumes, each of $1 \mathrm{ml}$., of normal heparinized blood were placed in a series of $5 \mathrm{ml}$. screw-topped bottles and small pieces of various materials added to the blood. The bottles were rotated on a mechanical mixer kept at $37^{\circ} \mathrm{C}$., at 33 revolutions per minute, for one hour and six hours respectively. The results are shown in Table $I$. Whereas no significant lysis developed in the blood samples to which nothing had been added, the presence of cotton (lint), Teflon felt, or polythene tubing all caused some lysis, although less than that caused by glass beads. Similar amounts of lysis developed when the experiment was repeated using normal cells suspended in (a) the patient's serum and (b) an equal volume of normal serum.

In view of the above considerations and because it appeared unlikely that the patient's haemolytic anaemia would disappear spontaneously, it was decided to explore and examine the left atrium. 
TABLE I

EFFECT IN VITRO OF VARIOUS MATERIALS ON NORMAL BLOOD

(a) Heparinized whole blood, rotated at $37^{\circ}$ C. at 33 revolutions per minute for one hour and fo. si $x$ hours

$\%$ Haemolysis

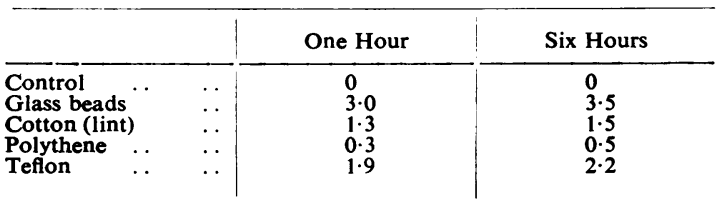

(b) Washed cells and equal volume of patient's serum and normal serum, respectively, rotated at $37^{\circ}$ C. at 33 revolutions per minute for one hour

\begin{tabular}{|c|c|c|c|}
\hline \multicolumn{4}{|c|}{$\%$ Haemolysis after One Hour } \\
\hline & & $\begin{array}{l}\text { Washed Cells and } \\
\text { Patient's Serum }\end{array}$ & $\begin{array}{l}\text { Washed Cells and } \\
\text { Normal Serum }\end{array}$ \\
\hline $\begin{array}{l}\text { Control } \\
\text { Glass beads } \\
\text { Cotton (lint) } \\
\text { Polythene } . . \\
\text { Teflon }\end{array}$ & \begin{tabular}{l|}
$\ldots$ \\
$\ldots$ \\
$\cdots$ \\
$\ldots$
\end{tabular} & $\begin{array}{l}0 \cdot 1 \\
3 \cdot 8 \\
0 \cdot 9 \\
0 \cdot 5 \\
0.9\end{array}$ & $\begin{array}{l}0.1 \\
3.7 \\
1.2 \\
0.6 \\
1 \cdot 1\end{array}$ \\
\hline
\end{tabular}

SeCond Operation (April 12, 1961).-The chest was entered through a left antero-lateral thoracotomy. The left atrium was explored, but access to the septum was very difficult. Body cooling was started and hypothermic arrest was achieved at $23^{\circ} \mathrm{C}$. The original Tefion patch was palpable in the septum and its upper rim was found to be covered by endothelium. Just above the aortic cusp of the mitral valve there was a little cul-de-sac, in the floor of which was bare Teflon. This cul-de-sac seemed to be in close relationship to the partial cleft in the mitral valve. The adjacent edges of endocardium were sutured over the bare area to provide a complete and satisfactory cover. No attempt was made to repair the mitral valve, as it was difficult to determine the precise abnormality, and no significant incompetence had been revealed by the palpating finger. The surgical anatomy as found at operation is illustrated diagrammatically in Fig. 4.

The operation was completed satisfactorily, the patient was rewarmed, the heart was defibrillated with a single $200 \mathrm{v}$. shock, and sinus rhythm was restored. During the operation 10 litres of blood was administered to prime the extracorporeal circulation and to replace the operative blood loss.

The patient made a satisfactory recovery from the operation and has remained well for the four months that he has now been followed. The plasma haemoglobin fell to the normal level $(<4 \mathrm{mg}$. per $100 \mathrm{ml}$.) and the haemoglobinuria disappeared by the second day after the operation (Fig. 3). The haemoglobin, which was $14 \mathrm{~g}$. per $100 \mathrm{ml}$. at the end of the operation (due to the transfusion of blood), has remained at the normal level subsequently. The reticulocyte count fell to $<1 \%$, haptoglobins are now present in the serum in normal amounts, and the erythrocytes are normal in appearance; cell fragments are no longer circulating. The serum iron level, however, remains raised $(217 \mathrm{mg}$. per $100 \mathrm{ml}$.) and the urine deposit still contains large amounts of haemosiderin, presumably because iron is still being shed from the previously heavily loaded tubular cells of the kidney.
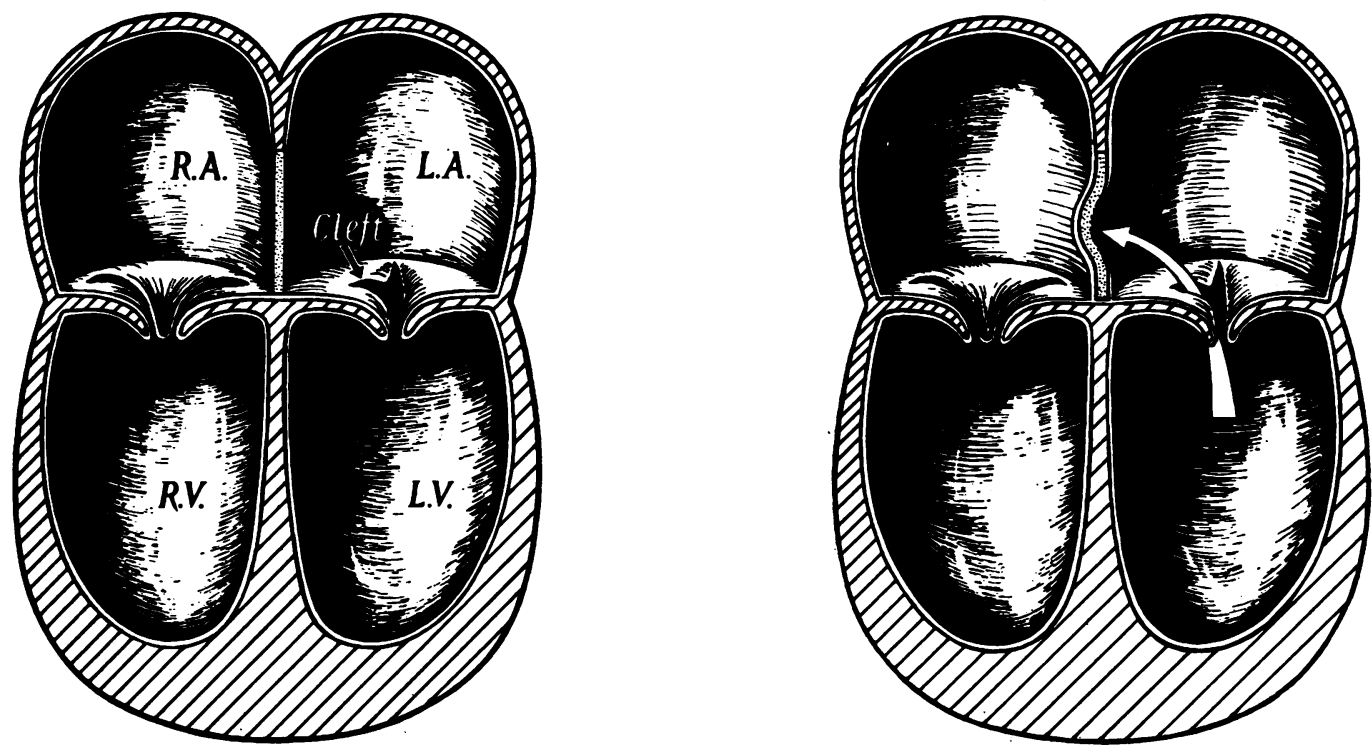

FIG. 4.-Diagrammatic representation to show the Teflon felt patch in position, the partial cleft in the mitral valve, and the mechanism whereby the jet of blood was impinging against the patch causing the cul-de-sac and preventing endothelialization of the Teflon. 


\section{Discussion}

Normal erythrocytes appear to undergo lysis if brought in contact with certain foreign surfaces, but the exact conditions under which this occurs and the mode of lysis are obscure.

In an experimental study with dogs, Stohlman, Sarnoff, Case, and Ness (1956) demonstrated the production of an intravascular haemolytic anaemia when a lucite conduit containing a Hufnagel ballvalve was fixed between the apex of the left ventricle and the thoracic aorta. They postulated that the red cells were damaged because they were forced by the flow pressure between the rigid ball and the rigid valve housing. It seemed unlikely that the material per se was the cause of trauma to the red cells, as the substitution of a 2-in. lucite tube for a segment of the thoracic aorta in a further series of animals did not result in the development of a haemolytic process. However, experiments carried out by Stewart and Sturridge (1959), who studied the haemolysis occurring in blood flowing through different types of tubing, showed that most occurred with rubber tubing, but that significant amounts, nevertheless, occurred in P.V.C. or " tygon" tubing or in " beverage hose." Teflon is generally considered to be an inert plastic, but the crude experiment described earlier makes it appear that its presence, too, can lead to haemolysis.

There seems no doubt that this patient's haemolysis was caused by mechanical conditions in the heart, presumably by a regurgitant jet of blood being driven against bare Teflon felt. Whether it was the presence of Teflon alone, or the lack of endothelial covering leading to a roughened surface, or the turbulence of the blood which caused the haemolysis remains uncertain. Possibly all three factors played a part. What is clear is that covering the bare area of Teflon with endocardium was followed by immediate cessation of haemolysis and the recovery of the patient.

It is well known that complete correction of mitral incompetence in the repair of an atrioventricular canal is difficult to achieve. Our $\vec{\circ}$ experience with this case suggests that it is $\overrightarrow{\vec{H}}$ undesirable to expose bare Teflon felt to a mitral $\stackrel{\omega}{\sigma}$ regurgitant jet. This can be best achieved by $\overrightarrow{\vec{*}}$ coverıng the left atrial side of the Teflon patch $\stackrel{x}{-}$ with free pericardial graft; the right side is left $\vec{\sigma}$ uncovered so that it may more readily be incorporated into the tissues. We have used this of techniaue in repairing the atrio-ventricular canal in our subsequent patients.

Since we wrote this paper other patients in $\vec{\nabla}$ whom an atrio-ventricular canal has been repaired $\mathbb{D}$ with Teflon felt have been investigated. A case $\mathbb{D}$ with similar haemolysis was discovered, but the patient's condition was not severe enough to require blood transfusion or a second operation.

\section{SUMmary}

A patient who underwent open cardiac surgery for repair of an ostium primum defect developed a severe intravascular haemolytic anaemia after $\stackrel{D}{\mathbb{D}}$ operation. This was caused by mechanical condi- $\Omega$ tions in the heart, a regurgitant jet of blood being $\overrightarrow{\overrightarrow{0}}$ driven against bare Teflon felt. Covering the bare $\exists$ area of Teflon led to immediate cessation of haemolysis and recovery of the patient.

A method is described for preventing this hazard of open cardiac surgery.

\section{REFERENCES}

Stewart, J. W., and Sturridge, M. F. (1959). Lancet, 1, 340. Stohlman, F., Sarnoff, S. J., Case, R. B., and Ness, A. T. (1956). Circulation, 13, 586. 